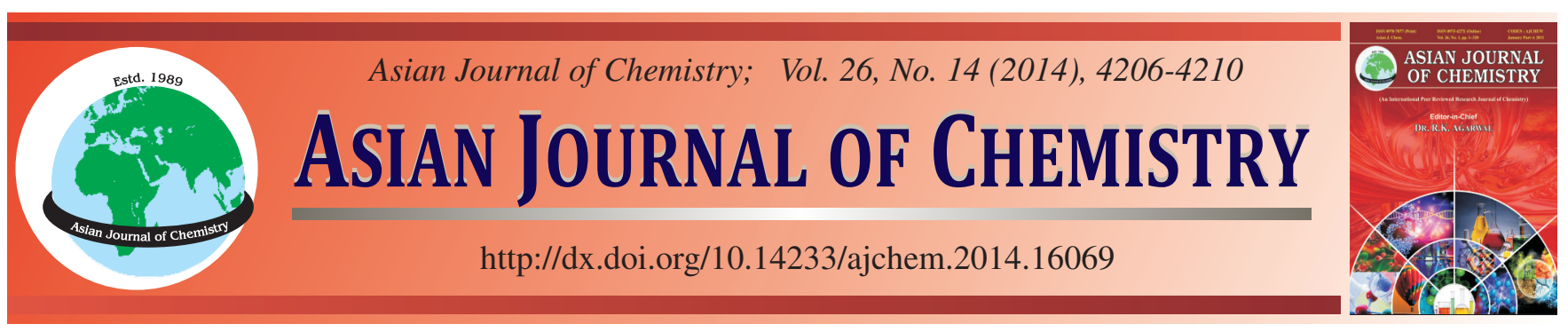

\title{
Large-Scale Extraction and Purification of Microcystin-LR by Macroporous Resins
}

Y.Q. CAO, N. WeI, A.J. GonG ${ }^{*}$ and L.N. QIU

School of Chemistry and Biology Engineering, University of Science and Technology Beijing, Beijing 100083, P.R. China

*Corresponding author: Tel: +8610 82375661; E-mail: gongaijun5661@ustb.edu.cn

Received: 19 July 2013;

Accepted: 1 November 2013;

Published online: 5 July 2014;

AJC-15442

\begin{abstract}
An effective method for large-scale extraction and purification of microcystin-LR (MC-LR) was established. $660 \mathrm{~mL}$ supernatant centrifugated from algae serum was absorbed by resin D101. The impurities on D101 resin were removed by $40 \%$ acetic acid ( $3 \mathrm{~L})$, deionized water $(2.5 \mathrm{~L}), 20 \%$ acetone $(2 \mathrm{~L})$ and $10 \%$ ethanol $(2 \mathrm{~L})$ in turn. Thus microcystin-LR on D101 resin was purified. The adsorbed microcystin-LR was eluted from the resin with $70 \%$ methanol $(9 \mathrm{~L})$. The eluent was concentrated by rotary evaporation at 80 ${ }^{\circ} \mathrm{C}$. The quality of microcystin-LR in the crude extract was $2075.5 \mu \mathrm{g}$. The recovery rate was $79.71 \%$. In addition, the method of getting microcystin-LR by preparative chromatography is established. The purity of the product was $95 \%$.
\end{abstract}

Keywords: Microcystin-LR, Macroporous resin, Extraction, Purification.

\section{INTRODUCTION}

Microcystins (MCs) are cyanobacterial secondary metabolites $^{1}$, it is cyclic heptapeptide molecules and molecular weight is 800-1100. Most of them are water soluble and have good chemical durability ${ }^{2}$. Microcystins are highly toxic with liver as the target organ. Inside the hepatocytes, microcystins bind to protein phosphatases 1 and $2 \mathrm{~A}$ by covalent bonding ${ }^{3}$, inhibit activity, it can cause hepatomegaly and make animal dead, it also has a high capacity to induce tumors in liver ${ }^{4}$. Microcystins cause the potential health hazard to aquatic animals and plants and humans ${ }^{5}$. At least 85 variants are known so far ${ }^{6}$. The World Health Organization (WHO) has suggested the concentration of microcystins in drinking water cannot be more than $1.0 \mu \mathrm{g} / \mathrm{L}^{7}$. Most studies have reported the high potential carcinogenic effect of long-term drinking water contaminated by microcystins ${ }^{8}$. Among all of the variants of microcystins , microcystin LR (MC-LR) is the most common, toxic and acute harmful ${ }^{9}$. Considerable researches on microcystins have been carried out, such as its characterizations ${ }^{10}$, environmental behavior ${ }^{11}$, toxicity assessment and toxic mechanism ${ }^{12-13}$, but many problems still existing. In the study of cyanophycean toxin, the demands for standard microcystins increase. Microcystins variants are varied, it need standard microcystins to identify during the research ${ }^{14}$. However, highly purified microcystin-LR is so expensive that further research of microcystins in China is hindered. There have been many reports on miniature extraction and purification of microcystin$\mathrm{LR}^{15-18}$, but large-scale purification methods have not been reported. This paper is mainly about the method on extraction and purification of microcystin-LR by macroreticular resin. The product of microcystin-LR was later isolated by high performance liquid chromatography (HPLC) from crude product and identified by electrospray mass spectrometry. This study is significant to obtain large-scale highly purified microcystin-LR.

\section{EXPERIMENTAL}

Algae paste was collected from Chaobai river in Tianjin. The microcystin-LR standards were purchased from Alexis Company. Methanol, ethanol, acetic acid and acetone of analytical grade, trifluoro-acetic acid (TFA) of HPLC grade, were all form Beijing Chemical Works. Ultra-pure water was obtained from a Milli-Q Synthesis system (Millipore Ltd., USA). Resin D101 was obtained from Tianjin Guangfu Fine chemical industry research institute.

Detection conditions of HPLC: High performance liquid chromatography (HPLC, SHIMADZU, Japan), retrofitted with UV detection and LC Solution Lite workstation was used for identification of microcystin-LR. HPLC analysis was performed using LC column (Inertsil ODS-5 $\mu \mathrm{m}, 250 \times 4.6 \mathrm{~mm}$, DIKMA, USA). The mobile phase was methanol: ultra-pure water $(0.1 \%$ TFA $)=60: 40(\mathrm{v} / \mathrm{v})$, flow rate was $1 \mathrm{~mL} / \mathrm{min}$ and injection volume was $20 \mu \mathrm{L}$. The column temperature was $25^{\circ} \mathrm{C}$ and the detection wavelength was $239 \mathrm{~nm}$.

Extraction of microcystin-LR from algae paste: Algal cells were freeze-thawed for extraction. Next, the solution with 
algae cells were centrifugated at $4{ }^{\circ} \mathrm{C}$ and $8000 \mathrm{rpm}$ for $20 \mathrm{~min}$. Microcystin-LR in supernatant was analyzed by HPLC. Microcystin-LR concentration was $4 \mu \mathrm{g} / \mathrm{mL}$. Supernatant were stored at $-10{ }^{\circ} \mathrm{C}$ and light-free.

Purification of microcystin-LR from supernatant: Supernatant $(660 \mathrm{~mL})$ was absorbed by resin D101, drip washed continuously with $40 \%$ acetic acid (3 L, $80 \mathrm{~mL} / \mathrm{min})$, deionized water $(2.5 \mathrm{~L}, 100 \mathrm{~mL} / \mathrm{min}), 20 \%$ acetone $(2 \mathrm{~L}, 120$ $\mathrm{mL} / \mathrm{min}), 10 \%$ ethanol ( $2 \mathrm{~L}, 120 \mathrm{~mL} / \mathrm{min}$ ) in order to purify microcystin-LR. The adsorbed microcystin-LR was eluted from the resin with $70 \%$ methanol $(9 \mathrm{~L}, 120 \mathrm{~mL} / \mathrm{min})$. The eluent was collected continuously in the brown flask and every $500 \mathrm{~mL}$ was in one flask. The eluent between 1.5-7.5 L was concentrated by rotary evaporation at $80^{\circ} \mathrm{C}$. The crude extract constant volume was $50 \mathrm{~mL}$ by adding $70 \%$ methanol, then filtered through $0.45 \mu \mathrm{m}$ organic filter paper and analyzed by HPLC to determine concentration and recovery of microcystinLR. A large number of crude extract obtained was concentrated at $80^{\circ} \mathrm{C}$. New crude extract with high concentration of microcystin-LR was obtained (Fig. 1). The microcystin-LR recovery was calculated using the following equation:

$$
\mathrm{R}=\frac{\mathrm{m}_{\mathrm{MC}-\mathrm{LR}[\text { crude-extract }]}}{\mathrm{m}_{\mathrm{Mc}-\mathrm{LR}[\text { supernatant }]}} \times 100 \%
$$

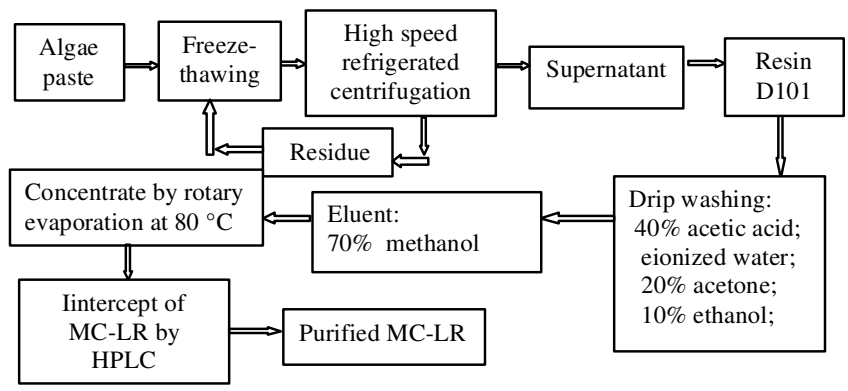

Fig.1. Process chart of microcystin-LR (MC-LR) purification

Preparation of microcystin-LR by HPLC from crude extract: $0.45 \mu \mathrm{m}$ organic membranes were used to filter crude extract, $20 \mu \mathrm{l}$ was injected into HPLC. A brown reagent bottle was used to collect the affluent, which was detected between 0.66-1.06 min after microcystin-LR's characteristic peak appeared. The volume of collection was nearly $0.4 \mathrm{~mL}$ per time, after repetitive operation, it could reach $30 \mathrm{~mL}$. The concentration and purity of microcystin-LR in the collection was determined by HPLC and microcystin-LR was identified by mass spectrometry. The electrospray mass spectrometry analysis ${ }^{19,20}$ was performed by Bruker Apex IV FTMS of Peking University.

\section{RESULTS AND DISCUSSION}

The small-scale extraction and purification of microcystinLR by resin D101 had been established by our lab. In order to deal with the large amount of supernatant and obtain microcystin-LR with high concentration, small-scale experiment was scaled up.

Determination of optimal sample loading amount: The resin D101 column chromatography was performed on a lowpressure glass chromatographic column $(24 \#$ F80 L $=610 \mathrm{~mm}$
$150 \mathrm{~cm}$, Tianjin Xuehui Glass Inc, China) filled with $3 \mathrm{Kg}$ resin D101. The length of the resin column was $60 \mathrm{~cm}$. Supernatant (concentration of microcystin-LR is $4 \mu \mathrm{g} / \mathrm{mL}$ ) was absorbed by column with flow rate of $30 \mathrm{~mL} / \mathrm{min}$. The eluent was collected sequently in the brown volumetric flask and every $50 \mathrm{~mL}$ was in one flask numbered in sequence. These eluent were concentrated to $10 \mathrm{~mL}$, respectively. Finally, these crude extract was submitted to HPLC analysis ${ }^{21}$. The result was shown in Fig. 2: microcystin-LR appeared in the eluent after volume of $650 \mathrm{~mL}$ and reached to saturation until the volume of $850 \mathrm{~mL}$. To avoid of wasting microcystin-LR, volume of $660 \mathrm{~mL}$ was chosen to be the optimal sample loading amount when microcystin-LR concentration was $4 \mu \mathrm{g} / \mathrm{mL}$.

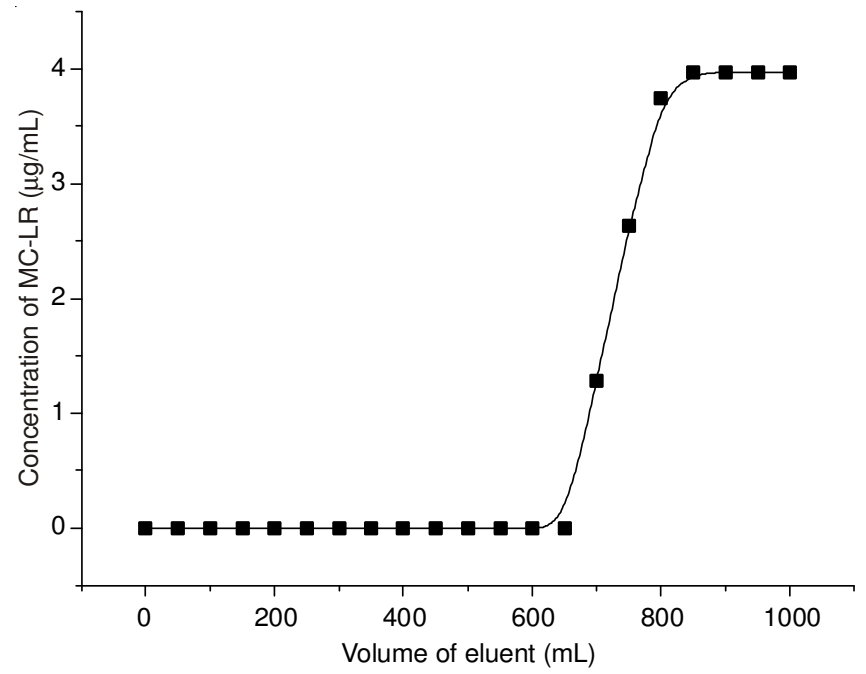

Fig. 2. Determination of optimal sample loading amount

Determination of drip washing volume: According to the two factors proportion of small-scale experiment and largescale one-volume of resin and sample loading, the drip washing volume was scaled up too. The details of experimental condition and recovery of microcystin-LR were shown in Table-1. Experiment I was small-scale; II was large-scale. The microcystin-LR recovery of II was higher than that of I. It may because the amount of microcystin-LR used in II was quite larger than I, during the drip-washing, the proportion of wastage decreased and the recovery was higher than I. So the optimal condition of drip washing was $40 \%$ acetic acid (3 L), deionized water (2.5 L), $20 \%$ acetone ( $2 \mathrm{~L}), 10 \%$ ethanol (2 L).

Determination of eluent volume: Supernatant $(660 \mathrm{~mL})$ was absorbed by a column; the condition of drip washing was the same as experiment II. Eluent was $70 \%$ ethanol. The fraction was collected continuously in the brown flask and every $500 \mathrm{~mL}$ was in one flask numbered in sequence. These eluent were concentrated to $10 \mathrm{~mL}$, respectively ${ }^{22}$ and submitted to HPLC analysis. The elution curve of microcystin-LR was shown in Fig. 3. microcystin-LR appeared in the eluent after $1.5 \mathrm{~L}$ and the concentration reached to maximum at $3 \mathrm{~L}$; then it decreased and disappeard at $9 \mathrm{~L}$. In order to wash all microcystin-LR down, $9 \mathrm{~L}$ was chosen to be the optimal volume of $70 \%$ ethanol. Because the volume of eluent was large, it needed a lot time to be concentrated, eluent between 1.5-7.5 L were chosen to be concentrated by rotary evaporation. 
TABLE-1

EFFECT OF DRIP WASHING VOLUME ON MICROCYSTIN-LR (MC-LR) RECOVERY

\begin{tabular}{ccccccc}
\hline Experiment & $\begin{array}{c}\text { Volume of sample } \\
\text { loading }(\mathrm{mL})\end{array}$ & $\begin{array}{c}\text { Volume of 40 \% } \\
\text { acetic acid }(\mathrm{L})\end{array}$ & $\begin{array}{c}\text { Volume of deionized } \\
\text { water }(\mathrm{L})\end{array}$ & $\begin{array}{c}\text { Volume of 20 \% } \\
\text { acetone (L) }\end{array}$ & $\begin{array}{c}\text { Volume of 10 \% } \\
\text { ethanol (L) }\end{array}$ & $\begin{array}{c}\text { Recovery of } \\
\text { MC-LR (\%) }\end{array}$ \\
\hline I & 8 & 0.10 & 0.05 & 0.15 & 0.15 & 61.36 \\
II & 660 & 3 & 2.5 & 2 & 2 & 76.37 \\
\hline
\end{tabular}

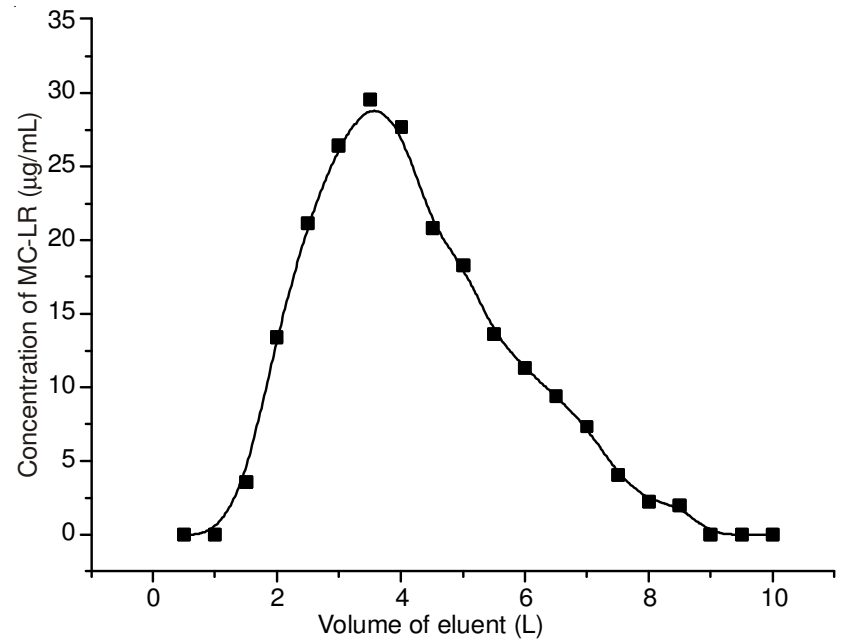

Fig. 3. Elution curve of microcystin-LR (MC-LR) in $660 \mathrm{~mL}$ supernatant

After repeated experiments, it was confirmed that the average recovery of microcystin-LR was $79.71 \%$.

Determination of rotary evaporation temperature: Three samples of the crude extract $(10 \mathrm{~mL}, 41.51 \mu \mathrm{g} / \mathrm{L})$ were taken, adding $70 \%$ methanol respectively to make the volume reach to $500 \mathrm{~mL}$ and evaporated to $10 \mathrm{~mL}$ at 70,80 and $90{ }^{\circ} \mathrm{C}$, respectively. The time was recorded. The concentration of microcystin-LR was detected. From Table-2, it could be seen that under the premise of the same volume after spin steaming, the recovery of the microcystin-LR decreased while the spin steaming temperature increased and the time was shortened. Considering the influence of recovery and time, $80{ }^{\circ} \mathrm{C}$ was chosen for experiment.

\begin{tabular}{cccc}
\multicolumn{4}{c}{ TABLE-2 } \\
\multicolumn{4}{c}{ EFFECT OF ROTARY EVAPORATION TEMPERATURE } \\
ON MICROCYSTIN-LR (MC-LR) RECOVERY
\end{tabular}

The stability of the experiment at $80{ }^{\circ} \mathrm{C}$ was tested. The time was obtained by record that it took $11 \mathrm{~h}$ to spin steam eluent from $6 \mathrm{~L}$ to $50 \mathrm{~mL}$. In order to explore the influence of the long-time steam heating on the recovery, crude extract (50 $\mathrm{mL}, 60.65 \mu \mathrm{g} / \mathrm{L})$ were taken, adding methanol (100 mL, $70 \%$ ) as the sample 1 . The sample 1 was rotated for $11 \mathrm{~h}$ without vacuum by the rotary evaporator and then spins steamed for $0.5 \mathrm{~h}$ with vacuum until the volume reached to $50 \mathrm{~mL}$; the reclaimed extract was numbered as sample 2 . The results were shown in Fig. 4, after heated $11 \mathrm{~h}$ at $80{ }^{\circ} \mathrm{C}$, the recovery of microcystin-LR was $91.87 \%$ and it was acceptable. Hence, $80{ }^{\circ} \mathrm{C}$ was chosen as the rotary evaporation temperature.

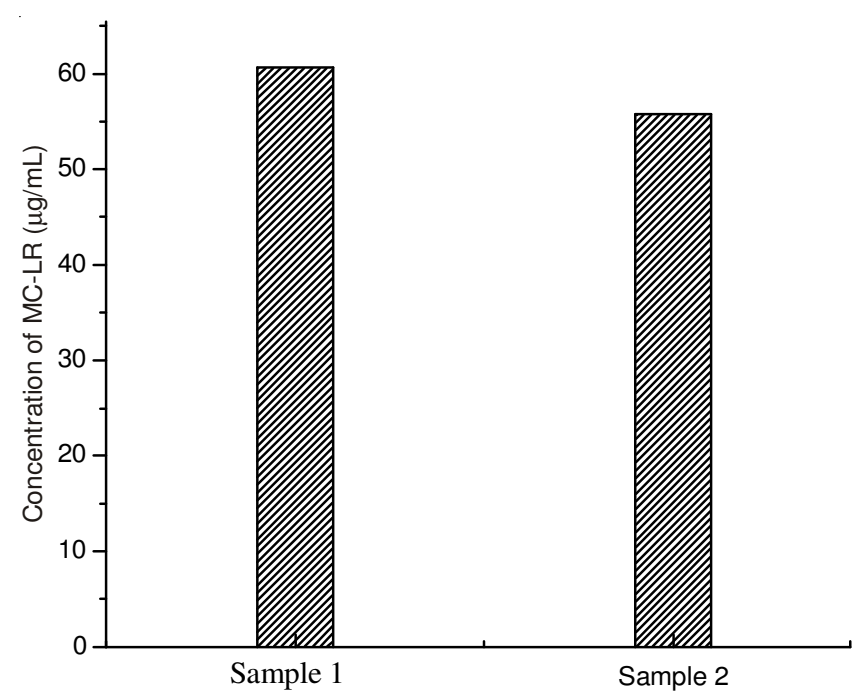

Fig. 4. Effect of rotary evaporation for $11 \mathrm{~h}$ at $80^{\circ} \mathrm{C}$ on microcystin-LR (MC-LR) recovery

Test experiment: According to the optimum experiment conditions, the test experiments were began to detect the recovery of microcystin-LR in supernatant. As Table-3 shown, the average recovery was $79.71 \%$. It could be certified that the method was stable and useful.

\begin{tabular}{cccc}
\multicolumn{4}{c}{ TABLE-3 } \\
\multicolumn{4}{c}{$\begin{array}{c}\text { DETERMINATION RESULTS OF } \\
\text { MICROCYSTIN-LR (MC-LR) RECOVERY }\end{array}$} \\
\hline Times & $\begin{array}{c}\text { Loading quantity } \\
\text { of MC-LR }(\mu \mathrm{g})\end{array}$ & $\begin{array}{c}\text { Recycling quantity } \\
\text { of MC-LR }(\mu \mathrm{g})\end{array}$ & $\begin{array}{c}\text { Recovery } \\
(\%)\end{array}$ \\
\hline 1 & 2640 & 2141 & 81.10 \\
2 & 2640 & 2016 & 76.36 \\
3 & 2640 & 2205 & 83.52 \\
4 & 2640 & 2055 & 77.84 \\
Average & 2640 & 2104 & 79.71 \\
\hline
\end{tabular}

Further purification of crude extract: The crude extract obtained by repetitive experiments was mixed and rotary evaporated to $15 \mathrm{~mL}$. The liquid in the round bottom flask was sucked out by a straw and numbered as sample 1; then the attachments on the round bottom flask wall was washed down with $70 \%$ methanol and numbered as sample 2. The two samples were centrifuged at $4000 \mathrm{rpm}$ for $5 \mathrm{~min}$ and then supernatant was sucked out by a straw. Finally, the concentration of microcystin-LR was determined. As the Fig. 5 shown, there was no microcystin-LR in sample 1 , but there were many other substances which retention time were between 2-6 min. Compared with sample 1, there were more microcystin-LR and less substances appeared between 2-6 min in sample 2 . The characteristic peaks of microcystin-LR and other impurity could be clearly separated. So after further concentration and centrifugation, microcystin-LR in the crude extract could be 


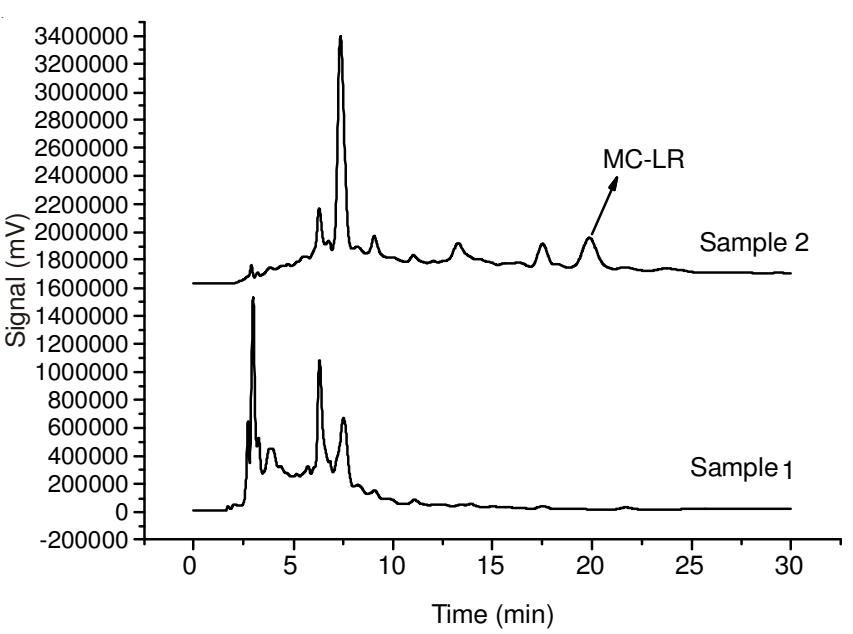

Fig. 5. Effect of concentrated by rotary evaporation and centrifugation on microcystin-LR (MC-LR) purification

further purified and the concentration could be highly improved, which was very beneficial for intercepting the highly purified microcystin-LR by HPLC.

Chromatography preparation of microcystin-LR: The effluent was collected when the microcystin-LR peak appeared in the detector, every 8 seconds for a sample, numbered in sequence, five more samples were intercepted after peak ended. 18 samples were obtained and determined the concentration separately. The result was shown in Fig. 6, microcystin-LR began to appear in the sample 3 and concentration reached maximum until the sample 6,7 , then it began to diminish gradually. Other substances were determined after microcystin-LR peak in sample 12 . So, in order to receive highly concentrated and purified microcystin-LR, sample $4-8$ were chosen to be collected; that was the fraction between 0.66-0.16 min after the microcystin-LR peak appeared. The result was shown in Fig. 7 , microcystin-LR concentration was $7 \mu \mathrm{g} / \mathrm{mL}$, purity was $95 \%$. microcystin-LR's molecular formula is $\mathrm{C}_{49} \mathrm{H}_{74} \mathrm{~N}_{10} \mathrm{O}_{12}$. Molecular weight is $995^{23}$. According to Fig. 8-a, 8-b, electrospray mass spectrometry analysis of standard microcystin-LR and purified microcystin-LR could certify that the main product was microcystin-LR.

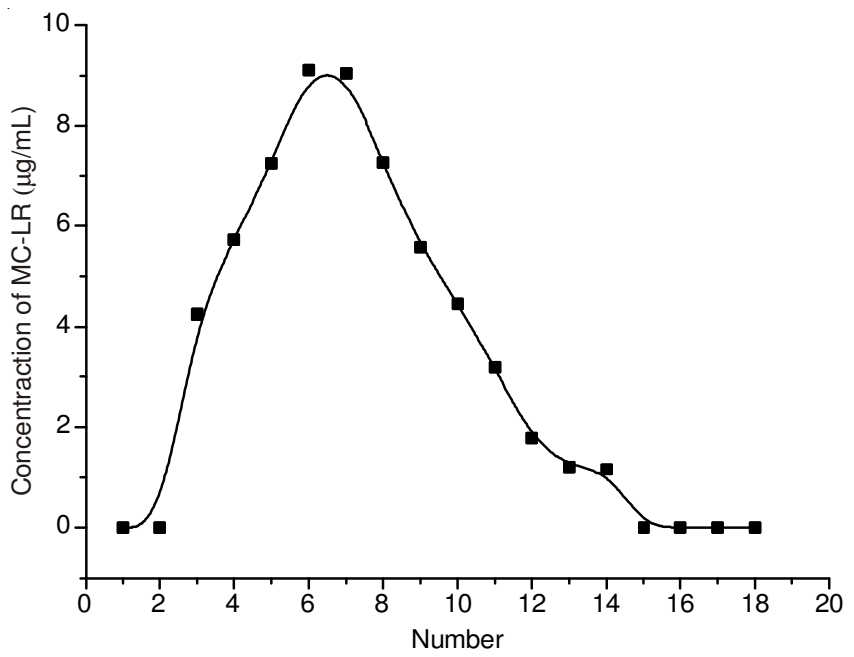

Fig. 6. Interception curves of microcystin-LR (MC-LR) by HPLC

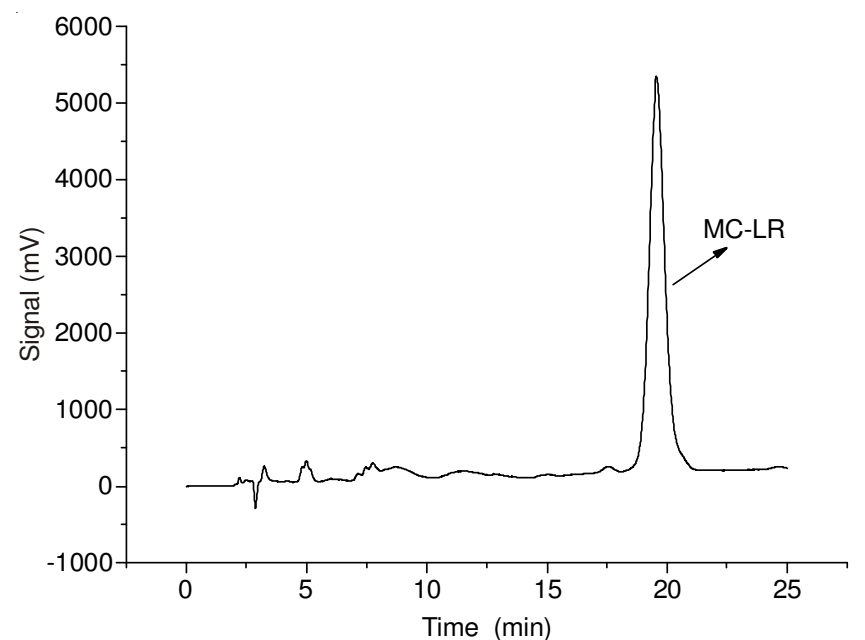

Fig. 7. HPLC chromatogram of purified microcystin-LR (MC-LR)

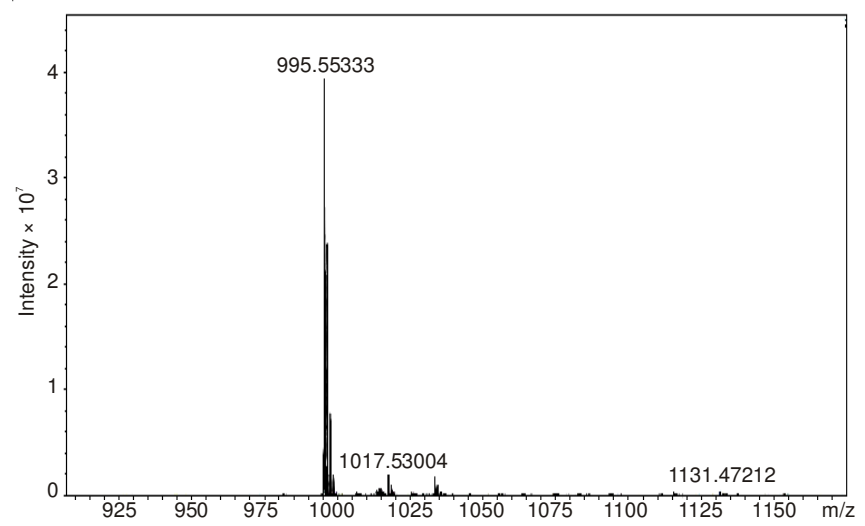

Fig. 8. (a) Electrospray mass spectrometry analysis of standard microcystin-LR

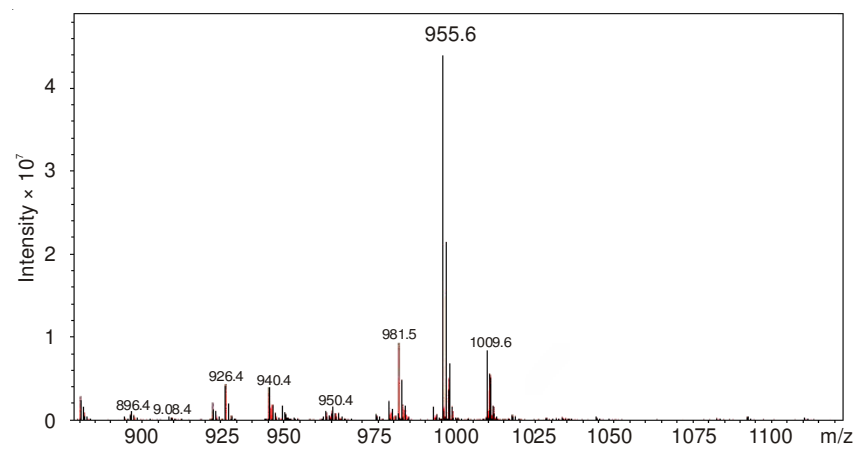

Fig. 8 (b) Electrospray mass spectrometry analysis of purified microcystin-LR

\section{Conclusions}

- An effective method for large-scale extraction and purification of microcystin-LR was established. $660 \mathrm{~mL}$ supernatant centrifugated from algae serum can be processed once by resin D101.40\% acetic acid (3 L), deionized water $(2.5 \mathrm{~L})$, $20 \%$ acetone (2 L) and $10 \%$ ethanol (2 L) were applied to get rid of the impurities from the resin. $70 \%$ methanol (9 L) was used to elute the microcystin-LR from the resin. After concentrated by rotary evaporation at $80{ }^{\circ} \mathrm{C} .2075 .5 \mu \mathrm{g}$ microcystinLR was obtained, with the recovery rate of $79.71 \%$.

- The method of getting microcystin-LR by preparative chromatography was established, the purity of the product was $95 \%$. 


\section{ACKNOWLEDGEMENTS}

This study was financially supported by Project of Engineering Research Institute of University of Science and Technology Beijing (YJ2009-016).

\section{REFERENCES}

1. L. Spoof, M.R. Neffling and J. Meriluoto, J. Chromatogr. B, 877, 3822 (2009).

2. D. Gutiérrez-Praena, Á. Jos, S. Pichardo, I.M. Moreno and A.M. Cameán, Food Chem. Toxicol., 53, 139 (2013).

3 V.R. Beasley, R.A. Lovell, and K.R. Holmes. Val R. Beasley, Randall A. Lovell, J. Toxicol. Environ. Health A, 61, 281 (2000).

4. A.R. Humpage and S.J. Hardy, J. Toxicol. Environ. Health A, 61, 155 (2000).

5. World Health Organization, WHO Guidelines for Drinking-Water Quality Recommendations Chemical Fact, Geneva, Switzerland, edn 3 (2004).

6. I. Chorus and J. Bartram, Toxic Cyanobacteria in Water: A Guide to their Public Health Consequences, Monitoring and Management, E \& FN Spon, London, p. 416 (1999).

7. WHO, Guidelines for Drinking Water Quality, Geneva, Switzerland (1998).

8. J. Chen, P. Xie, L. Li and J. Xu, Toxicol. Sci., 108, 81 (2009).

9. N.W. Carmichael, Sci. Am., 270, 78 (1994).

10. J.A. Zweigenbaum, J.D. Henion, K.A. Beattie, G.A. Codd and G.K. Poon, J. Pharm. Biomed. Anal., 23, 723 (2000).
11. Y. Polyak, T. Zaytseva and N. Medvedeva, Water Air Soil Pollut., 224, 1494 (2013).

12. J.E. Eriksson, D. Toivola, J.A.O. Meriluoto, H. Karaki, Y.G. Han and D. Hartshorne, Biochem. Biophys. Res. Commun., 173, 1347 (1990).

13. M. Runnegar, D.J. Seward, N. Ballatori, J.M. Crawforde and J.L. Boyer, Toxicol. Appl. Pharmacol., 161, 40 (1999).

14. M. Thirumavalavan, Y.L. Hu and J.F. Lee, Toxicol. Environ. Chem., 95, 221 (2013).

15. W.Y. Zhang, N. Han, L.R. Yao, X.L. Qiu and X.L. Chen, Adv. Mater. Res., 340, 318 (2011)

16. L.J. Zhang, L.H. Yin, Y.P. Pu and G.C. Zhu, J. Southeast Univ. (Nat. Sci. Ed.), 3, 446 (2005).

17. X. Wu, C. Wang, B. Xiao, Y. Wang, N. Zheng and J. Liu, Anal. Chim. Acta, 709, 66 (2012).

18. D. Pyo and C. Lim, J. Liq. Chromatogr. Rel. Technol., 29, 2691 (2006).

19. J.L. Wang, W.Y. Liang and L. Chen, J. Beijing Forestry Univ., 2, 184 (2010).

20. T. Wei, Z. Xiang X.G. Feng and J.J. Zhang, Jiangsu Environ. Sci. Technol., 5, 001 (2007).

21. W.W Zou, A.J. Gong, Y.Q. Cao, M.N. Liu and H.T. Yuan, Chem. Bioeng., 8. 025 (2008).

22. L.L. Liang, A.J. Gong, H.M. Li, Y.Q. Cao and B.Q. Li, Chin. J. Anal. Chem., 5, 040 (2010).

23. H.V. Frias, M.A. Mendes, K.H.M. Cardozo, V.M. Carvalho, D. Tomazela, P. Colepicolo and E. Pinto, Biochem. Biophys. Res. Commun., 344, 741 (2006). 